\title{
CONTROLE INTERNO EM MUNICÍPIOS BRASILEIROS: UMA ANÁLISE DAS CONTROLADORIAS-GERAIS DOS MUNICÍPIOS DIANTE DO MODELO DA CONTROLADORIA- GERAL DA UNIÁO*
}

\author{
Maria do Carmo Meirelles Toledo Cruz \\ Fundação Getúlio Vargas, Brasil \\ carminhameirelles@gmail.com \\ Mário Vinícius Claussen Spinelli \\ Fundação Getúlio Vargas, Brasil \\ mariovini@uol.com.br \\ Thomaz Anderson Barbosa Silva \\ Fundação Getúlio Vargas, Brasil \\ thomazanders@gmail.com \\ Marco Antonio Teixeira Carvalho \\ Fundação Getúlio Vargas, Brasil \\ marco.teixeira@fgv.br
}

\begin{abstract}
RESUMEN
La obligatoriedad de instituir un sistema de control interno en los municipios está establecida en la Constitución Federal Brasilera. Recientemente, e, inspirados posiblemente en el modelo de la Controladoria Geral da União (CGU), algunos municipios han creado contralorías para cumplir con el papel de unidad de control interno a nivel local. El presente trabajo analiza el rol que viene siendo desempeñando por esas contralorías, tomando como base el modelo implementado en el Gobierno Federal. El trabajo se realizó con base en un cuestionario de preguntas abiertas y cerradas, que fue enviado directamente a 34 municipios que cuentan con Contraloría General Municipal (CGM). Se concluyó, por un lado, que el papel desempeñado por la CGU desde su creación y la diseminación de su modelo a los municipios brasileros es todavía incipiente, y por otro lado, que las contralorías necesitan avanzar en el cumplimiento de la LAI y en la divulgación de sus actividades.

Palabras clave: Contraloría Municipal, Sistema de control interno, Gobierno local, Brasil.

* O presente estudo tem como referência os trabalhos apresentados no VI Encontro de Administração Pública e Governança, realizado em Belo Horizonte/MG, Brasil, de I6 a I 8 de novembro de 20 I 4 (Silva, T.; Cruz, M. y Spinelli, M. 20I4); e no XIX Congreso Internacional del CLAD sobre la Reforma del Estado y de la Administración Pública, realizado em Quito, Equador, de I I a I 4 de novembro de 20 I 4 (Teixeira, M.; Cruz, M. y Silva, T. 20 I 4). Foi revisado após discussóes dos congressos e contou, ainda, com contribuiçóes de pareceristas anônimos desta revista.
\end{abstract}




\title{
INTERNAL CONTROL IN BRAZILIAN MUNICIPALITIES AN ANALYSIS ON LOCAL COMPTROLLER GENERAL OFFICES, IN VIEW OF THE FEDERAL GOVERNMENT MODEL OF THE CONTROLADORIA-GERAL DA UNIÂO
}

\begin{abstract}
The obligation to constitute an internal control system within municipalities is established in the Federal Constitution of Brazil. Recently, and possibly inspired by the Controladoria Geral da União (CGU) model, some municipalities have created comptroller's offices to perform the role of internal control units at local level. The present paper analyses the role which is currently being performed by these comptroller offices, based on the model implemented in the Federal Government. The investigation was carried out based on a questionnaire with open and closed questions, which was directly transmitted to 34 municipalities which have a General Municipal Comptroller Office (CGM). It was concluded that the role performed by the CGU since its creation and the diffusion of its model to the Brazilian municipalities is still incipient, on the one hand, and that the comptroller offices need to make progress in the implementation of the LAI and in the dissemination of their activities, on the other.
\end{abstract}

Keywords: Municipal Comptroller's Office, Internal Control System, Local Government, Brazil. 


\section{INTRODUÇÃO}

Segundo a Constituição da República Federativa do Brasil de 1988 (CF1988), as três esferas de governo - União, estados e municípios - devem instituir sistemas de controle interno. Conforme o artigo 31 da Constituição, a fiscalização no âmbito municipal deve ser exercida pelo Poder Legislativo (mediante controle externo realizado pela Câmara dos Vereadores) e pelo Poder Executivo (por meio da criaçáo de sistemas municipais de controle interno). Reforçando tal concepção, o artigo 70 também afirma que cada Poder (Executivo, Legislativo e Judiciário) deve organizar seu próprio sistema de controle interno para exercer fiscalizações contábeis, financeiras, orçamentárias, operacionais e patrimoniais, de forma a garantir o cumprimento dos princípios de legalidade, legitimidade e economicidade, a aplicaçáo das subvençóes e a renúncia de receitas (Brasil 1988).

Considerando que já se passaram mais de vinte e cinco anos desde a edição do texto e não obstante tais previsóes legais, não foram muitos os municípios que criaram sistemas de controle interno. Ademais, não são muitas as prefeituras brasileiras que desenvolveram unidades de controle interno capazes de atuarem de forma mais incisiva no cumprimento de suas funçóes, em sua forma mais abrangente, parecendo haver um descompasso com o processo ocorrido no governo federal, caracterizado pelo fortalecimento da Controladoria-Geral da União (CGU) e pela sua consolidação como agência estatal de prevenção e combate à corrupção. Neste sentido, muitos órgáos municipais têm restringido suas atividades de controle interno ao exame da conformidade dos procedimentos administrativos, limitando-se a executar análises formais dos atos praticados, sem desenvolver políticas de prevençáo e controle mais amplas, como as desenvolvidas no governo federal.

Há, contudo, uma inovação em processo: alguns municípios brasileiros - talvez se baseando no modelo do governo federal e no reconhecimento social do papel que a CGU vem exercendo ou talvez como resposta à crescente demanda pela redução da impunidade, prevenção e combate à corrupção - vêm estruturando seus sistemas de controle interno (em alguns casos, alterando antigas estruturas) de forma a instituírem uma Controladoria-Geral do Município (CGM) como órgáo central do sistema de controle interno do Poder Executivo municipal. Indispensável observar, entretanto, se tal medida tem sido acompanhada da adequada estruturação dessas agências e se elas têm, de fato, cumprido seu papel como defensoras do patrimônio público.

Nesse contexto, o objetivo principal deste artigo é avaliar se os múltiplos papéis desempenhados pela CGU vêm sendo também adotados pelas 
controladorias municipais. Buscar-se-á ao longo deste texto, analisar se a transformação ocorrida na CGU na última década, aglutinando múltiplas atribuiçôes, foi elemento indutor para a criação das controladorias analisadas. Será identificado se ocorre processo de disseminação do modelo institucional da CGU para os governos locais. É importante salientar que será observado se os municípios utilizam-se do repertório de alternativas já construídas pela CGU para enfrentam problemas similares. Ressalta-se que náo existe uma única solução fechada e completa, cada município implementará transformações para que os modelos de controle interno sejam adequados as suas especificidades (Farah 2006).

Para tal, o artigo foi estruturado em cinco partes. A primeira apresenta o papel do controle interno na administração pública identificando as mudanças em sua concepçáo na última década. Em seguida se apresenta o modelo de atuação da CGU descrevendo a evolução de suas competências. A terceira parte presta a se fazer a descrição da metodologia adotada. $\mathrm{Na}$ quarta parte é feita a análise dos resultados alcançados focando dois pontos específicos: a capacidade institucional dos órgãos (GPP 2003) e as funçóes desempenhadas, utilizam-se como parâmetro aquelas exercidas pela CGU (auditoria, corregedoria, ouvidoria, promoção da transparência e fomento ao controle social). Por fim, conclui-se que é possível identificar estágios diferenciados de municípios na estruturação das CGMs. Os resultados apontam que o controle interno é ainda uma área a ser aprimorada nos municípios e que há uma grande diversidade de modelos de CGMs.

Estudos mais aprofundados são necessários para identificar se a implementação dessas estruturas estáo avançando de forma incremental para as novas funcionalidades preconizadas para os sistemas de controle interno nos governos locais (Silva, Cruz y Spinelli 2014).

\section{O PAPEL DO CONTROLE INTERNO NA ADMINISTRAÇÃO PÚBLICA}

Segundo a CF-1988 as três esferas de governo - União, estados e municípios - devem instituir sistemas de controle interno (artigos 31 e 70). Este comando constitucional aponta para uma preocupação com o controle do governo e das políticas públicas.

Entretanto, observa-se que as atribuiçôes de um sistema de controle interno variam no decorrer dos últimos anos. O conceito mais tradicional de controle interno relaciona-se com o conjunto de açôes, métodos, procedimentos e rotinas que uma organizaçáo exerce sobre seus próprios atos, a fim de preservar a integridade de seu patrimônio e de examinar a compatibilidade entre as operaçóes desenvolvidas, os parâmetros preestabelecidos 
e os princípios pactuados (Spinelli 2008: 575).

Todavia, em especial após 2000, vem sendo debatida a necessidade de ampliação do escopo de atuação dos sistemas de controle interno. As novas funcionalidades do sistema de controle interno propostas por várias instituiçōes nacionais e internacionais envolvem auditoria, controle contábil, fiscalização de obras, acompanhamento de políticas públicas, exames de licitaçóes e contratos, promoção da transparência municipal, monitoramento da Lei de Acesso à Informação (LAI), capacitação dos servidores e estímulo ao controle social (INTOSAI 2007, CFC 2008, CONACI 2010, OCDE 2011).

Apontam para uma nova direção na defesa do patrimônio público, reprimindo desvios de recursos públicos, promovendo a transparência e o acesso à informação, criando canais de interação e de engajamento da sociedade para o controle social e reduzindo a impunidade. Indicam que os sistemas de controle interno precisam avançar no cumprimento da accountability (Silva, Cruz y Spinelli 2014).

O primeiro teórico a fazer a distinção entre mecanismos de accountability vertical e horizontal foi O’Donnell (1998). Segundo sua clássica distinçáo, enquanto a accountability vertical representaria a relação entre a população e as autoridades públicas e seria manifestada principalmente por meio das eleiçóes, a accountability horizontal estaria relacionada com a existência de agências estatais com o poder de realizar açóes de controle e fiscalização, mecanismo que a literatura usualmente denomina de checks and balances.

Com base nessa concepção, as controladorias estariam inseridas no conceito de accountability horizontal. Olivieri (2006) ressalta o seu papel, que concebe a mútua fiscalização e o controle entre os órgãos. Para Speck (2002), os controles internos possuem poder legal e de fato para realizar desde a supervisão de rotina até sançóes legais contra atos delituosos de seus congêneres do Estado. Podendo exercer também entre os Poderes, forma de controle denominada comumente como controle externo.

Há que se destacar, todavia, que, devido ao fato de as controladorias, assim como as demais unidades de controle interno, estarem configuradas como órgãos da própria estrutura organizacional, sua atuaçáo, não raramente, depende diretamente da vontade política dos Chefes do Executivo em prover condiçóes básicas para seu funcionamento, dotando-as, por exemplo, de orçamento e pessoal qualificado. A amplitude de sua abrangência também é de iniciativa do Executivo. Além disso, para que cumpram sua missão institucional, essas unidades devem possuir condiçóes 
mínimas de autonomia e independência para atuar com a devida imparcialidade, notadamente nas atividades de fiscalização e correição.

Para o seu bom desempenho é necessário que tenha capacidade institucional aqui entendida como a

[...] habilidade das administraçóes de cumprir com suas responsabilidades em um governo democrático: i) utilizar sabiamente os recursos públicos e direcioná-los para os objetivos desejados; ii) gerir programas e pessoas de forma eficiente; e iii) avaliar se os objetivos estão sendo alcançados (Ingraham 2007).

Portanto, o Poder Executivo para cumprir seus objetivos e atribuiçóes legais do controle interno - com eficiência, alcance e eficácia -, deve utilizar os recursos disponíveis por meio de instrumentos e ferramentas de gestão adequados, além da capacidade de articulação com os outros entes federados e demais parceiros (Veloso, Monastério, Vieira y Miranda 2011).

Com efeito, o não provimento dessas condiçóes pode prejudicar o resultado pretendido pelas controladorias, comprometendo seu papel de unidade responsável pela preservação do patrimônio público e consecução de políticas de prevenção e combate à corrupçáo. Essas políticas incluem atividades de caráter repressivo, a exemplo de auditorias e fiscalizaçóes, e da atividade correcional, mas também ações de cunho preventivo, como promoção da transparência e do acesso à informação e fomento ao controle social.

Como órgãos de controle interno, funcionalidades como a promoção da transparência e do acesso à informação são indispensáveis para o fortalecimento da democracia (Vieira 2013), uma vez que o poder público passa a ser exercido de forma aberta e permite que os cidadãos possam acompanhar e avaliar a gestão local.

Políticas de transparência e acesso à informação estão associadas à melhoria da gestão pública, são consideradas essenciais à prevenção e ao combate à corrupção (ONU 2003) e devem ocorrer de duas formas: a transparência ativa (com a informaçáo divulgada de forma espontânea pelo poder público) e passiva (acesso do cidadão à informação mediante solicitação aos órgáos governamentais). O presente artigo foca a transparência passiva, e analisa as solicitaçóes às CGMs, assim como suas respostas.

A transparência ainda é examinada quanto à visibilidade (seja ela dada proativamente ou por meio de respostas às solicitaçôes) e inferabilidade (facilidade de compreensão e de tirar conclusões), conforme preconizado 
por Angélico (2012). Essa opção deve-se ao pressuposto de que a resposta deve ser inteligível, fazendo sentido ao solicitante.

Neste contexto, será analisado, a seguir, o modelo da CGU como o órgão responsável pelo controle interno da administração pública federal brasileira. Seu formato atual é o resultado de diversas alteraçóes institucionais incrementais (Lindbloom 1959) que ocorreram de 1994 a 2006, as quais fizeram com que o órgão ampliasse o escopo de sua atuação, passando a desenvolver políticas de diferentes naturezas relacionadas à prevençáo e ao combate à corrupçáo.

\section{O MODELO ADOTADO PELA CONTROLADORIA-GERAL DA UNIÁO}

A criação da CGU representa inovação institucional no processo de controle dos governantes na democracia brasileira por várias razóes. Para entender sua trajetória singular, efetua-se um breve exame das modificaçôes das funçóes do controle interno na estrutura político-administrativa federal brasileira, ocorridas após a edição da CF. Isso porque, a partir do comando constitucional, os poderes das instituiçóes de controles externo e interno, foram reforçados, e ambas definidas como guardiâs da legalidade e probidade na gestão pública.

No momento pós-constitucional, o foco do controle interno federal pouco se modificou do panorama até então existente, concentrando-se nos exames da conformidade entre as atividades desenvolvidas e as normas e regulamentos existentes. Nessa conjuntura, as análises caracterizavam-se por um viés extremamente formal, limitado à área de contabilidade ou, em alguns casos, à simples verificaçáo da legalidade dos documentos comprobatórios dos procedimentos adotados, em detrimento de controles preventivos ou voltados para o exame dos resultados das políticas públicas.

Apenas a partir de meados da década de 1990, essa visão estritamente contábil e formal das auditorias e dos processos de controle interno modificou-se. As várias mudanças de nome e estrutura ocorridas durante a história do controle interno federal no Brasil, com criação e extinção de órgãos, além de movimentos alternados de centralização e descentralização do controle na esfera federal, não tinham sido capazes de aplacar o impulso legal-formal insculpido tanto nas normas regentes do assunto quanto nas estratégias, operaçôes e nos procedimentos utilizados pelas instituiçóes incumbidas de exercer o controle concreto.

Conforme destaca Balbe (2010), um marco dessa mudança ocorreu em 1994, com a criação da Secretaria Federal de Controle (SFC), dentro da es- 
trutura do Ministério da Fazenda. Segundo o autor, naquela oportunidade, considerando-se o momento histórico vivido (redemocratização do país, abertura de mercado, desenvolvimento das ideias que levariam à proposta da reforma gerencial do Estado) e a evolução obtida, é que a atividade de controle interno começa a ser vista como integrante da gestáo pública. Pode-se dizer que isso se alimentou também do momento de efervescência da chamada administração gerencial japonesa, com seu famoso ciclo PDCA (planejar, fazer, controlar e avaliar/agir corretivamente).

Para Olivieri (2010), o modelo de controle, nesse momento, caracteriza-se pela centralização (existência de um órgão central), descentralização geográfica (unidades regionais de controle interno nos estados), coordenação do sistema pelo órgão central, e predominância da fiscalização.

O controle interno, antes concentrado na verificaçáo de conformidade contábil e nas auditorias financeiro-contábeis, vai assimilando outras açôes e atividades, voltadas para a fiscalizaçáo de objetos no âmbito da execução dos diversos programas governamentais. Em suma, controlar náo se resume mais a auditar documentos ou processos, mas também a fiscalizar (se a obra foi realizada, se o produto foi entregue etc.).

Esse cenário já aponta para o próximo estágio da atividade de controle interno no âmbito do governo federal brasileiro, que coincide com o surgimento da CGU, no início de 2003. A SFC passa a integrar a CGU, que congrega também as atividades de Ouvidoria-Geral da União e de corregedoria, nos termos da Lei Federal N. ${ }^{\circ}$ 10.683/2003.

O primeiro aspecto a se notar é que o órgão central do controle interno do Poder Executivo federal, agora representado pela CGU, passa a fazer parte da estrutura da Presidência da República, enquanto a SFC estava subordinada ao Ministério da Fazenda. A mudança é significativa, com repercussóes nos campos prático, de condução da política de controle interno pelo Poder Executivo federal, e simbólico, no nível das expectativas e da relevância do tema perante os responsáveis por exercer o controle e a própria sociedade.

Posteriormente, houve alteração normativa para agregar às atribuiçóes da CGU as funções de prevenção e combate à corrupção e incremento da transparência da gestão na Administração Pública federal (Lei Federal 11.204/2005). Um pouco antes, em 2004, já havia sido criado o Conselho de Transparência Pública e Combate à Corrupção, que também foi inserido na estrutura da CGU. 
O controle interno assumia, naquela oportunidade, definitivamente, um papel de protagonista na gestáo das políticas públicas, que transcendia seus limites anteriores. Constatou-se que um controle bem estruturado e estrategicamente orientado poderia contribuir para a aderência aos parâmetros legais, para a boa execução dos programas de governo e, aqui a novidade, para prevenir a corrupção.

Isso porque, enquanto o modelo tradicional, com enfoque meramente formal, não demonstrava ser suficiente para salvaguardar os ativos. $\mathrm{O}$ histórico insulamento dos órgãos responsáveis por esse controle os distanciava da crescente participação social no acompanhamento das açóes de governo, e impedia que atendessem às novas demandas sociais e à necessidade de interação, cada vez mais frequente, entre Estado e sociedade. Para atender a essa nova perspectiva foi necessário modificar as instituiçóes do próprio Estado brasileiro, tornando-as capazes de interagir de forma mais dinâmica com a sociedade civil.

Nesse panorama, a criação da Secretaria de Prevenção da Corrupção e Informações Estratégicas, em 2006, fez com que a CGU expandisse sobremaneira os limites da sua atuação, passando, de forma contínua e sistematizada, a elaborar projetos, instituir programas e executar açóes especialmente direcionadas à promoçáo da integridade, ao aumento da transparência pública, à prevenção e ao combate da corrupção, e ao incremento da participação social no acompanhamento das políticas públicas.

No cenário atual, há um controle interno federal que se preocupa com a execução dos programas de governo (aferição dos resultados, qualidade dos serviços prestados, eficiência, eficácia e efetividade das políticas públicas), e constata que a essa orientação devem ser somadas todas as iniciativas de combate e prevenção da corrupção, na medida em que esta compromete de forma ampla o funcionamento do governo e também a confiança da sociedade nas instituiçóes públicas.

A partir dessa síntese, percebe-se que a estrutura da CGU surgiu de forma incremental (Lindbloom 1959) e hoje atua em quatro áreas fundamentais, inter-relacionadas entre si: auditoria, corregedoria, prevenção da corrupção, e ouvidoria.

Esse modelo tem servido de base para a criação das controladorias municipais. A ampliação do papel de tais instituiçóes ocorre em um ambiente marcado, em certa medida, pela demanda por maior controle, dada a percepçáo, por boa parte da sociedade, e não de forma injustificada, de que a corrupçáo atinge níveis elevados no país e a impunidade ainda prevalece. Nessa conjuntura, a criação de órgãos, com a função primordial 
de prevenir e combater o mau uso de dinheiro público, em tese, pode ser compreendida como estratégia de apelo popular, por atender à demanda por mais níveis de controle e redução da impunidade.

Resta saber se a criação dessas unidades administrativas, sempre cercada de muita expectativa, não passa de simples retórica ou se, de fato, estarão aptas a desenvolver atividades capazes de efetivamente prevenir e combater a corrupçáo, dada a importância e complexidade do fenômeno. Ou seja, resta saber se as atuais funçóes da CGU estáo de fato sendo reproduzidas nos municípios que instituíram suas controladorias.

\section{A PESQUISA DAS CGMs E SUA METODOLOGIA}

Em pesquisa bibliográfica sobre o tema, identificou-se que são comuns os estudos de casos únicos sobre o sistema de controle interno municipal, sobretudo na área de Contabilidade Pública (Soares 2012, Oliveira 2012, Tavares 2005). Contudo, diante da diversidade encontrada nos $5.570 \mathrm{mu}-$ nicípios brasileiros (IBGE 2013), são poucos os estudos comparados que trazem uma amostra mais diversa de municípios. Esforços interessantes, porém focando os Sistemas de Controle Internos e não as Controladorias Gerais dos Municípios, são as dissertaçóes de mestrado de Lima (2012) e de Balbe (2010). A primeira faz um estudo com uma amostra de $56 \mathrm{mu}-$ nicípios brasileiros que dispóem na Internet os regulamentos legais para a criação de Sistema de Controle Interno local; a segunda faz um estudo dos Sistemas de Controle Interno focado nas capitais brasileiras.

Com tais constataçóes - e como inexiste no Brasil relação oficial das estruturas de sistemas de controles internos municipais identificadas como CGM - optou-se por um estudo exploratório (Thiel 2014) sobre as controladorias municipais brasileiras, e por comparar as diferentes estruturas existentes, independentemente do porte do município, de sua localização geográfica, ou suas características socioeconômicas.

Para compor uma amostra que garantisse tal diversidade ao estudo, foi utilizado uma ferramenta de busca virtual. Para Branski (2004: 72), ferramentas de busca são sistemas especializados utilizados na recuperação de informaçóes na Internet. Eles coletam informações sobre os conteúdos dos sites e os armazenam em bancos de dados que estáo disponíveis para consulta. Realizando uma busca, o usuário poderá descobrir a localização exata das informaçóes que deseja. A pesquisadora afirma que o mecanismo de busca Google alcança resultados bastante satisfatórios pois "define seus resultados de acordo com o número de links apontando para cada um dos documentos armazenados em sua base de dados". Na prática, isso significa que aparecerão na pesquisa os sites mais citados na Internet. A premissa de 
pesquisas semelhantes indica que "os sites mais populares oferecem informaçôes de melhor qualidade” (Branski 2004: 73).

A amostra deste estudo, portanto, foi identificada a partir de uma busca no site do Google realizada no dia 5 de outubro de 2013. O termo de procura foi Controladoria-Geral do Município, assemelhando-se à caracterizaçáo da estrutura de controle interno no nível federal (CGU). Foram considerados todos os resultados obtidos nas 15 primeiras páginas que direcionavam a pesquisa para sites das CGMs ou do Poder Executivo municipal, com as informações correspondentes ao tema.

Tal ponto foi estabelecido no momento em que nenhum link relevante para a pesquisa foi encontrado a partir da página 12. Como resultado, formou-se uma amostra final com 34 municípios, ainda longe de representar o universo das localidades que possuem uma CGM como estrutura central do sistema de controle interno, mas diversa o bastante para compreender municípios de todas as regiôes brasileiras e de diferentes portes populacionais (Tabela 1). 
Tabela 1: Amostra da pesquisa

\begin{tabular}{|c|c|c|c|c|}
\hline ID & Município & UF & Regiáo & Populaçáo 2013* \\
\hline 1 & Aracruz & ES & Sudeste & 91.562 \\
\hline 2 & Arez & $\mathrm{RN}$ & Nordeste & 13.764 \\
\hline 3 & Araucária & PR & Sul & 129.209 \\
\hline 4 & Arinos & MG & Sudeste & 18.198 \\
\hline 5 & Belo Horizonte & MG & Sudeste & 2.479 .175 \\
\hline 6 & Boa Vista & $\mathrm{RR}$ & Norte & 308.996 \\
\hline 7 & Canoas & RS & Sul & 338.531 \\
\hline 8 & Corumbá & MS & Centro-Oeste & 107.347 \\
\hline 9 & Cristino Castro & PI & Nordeste & 10.164 \\
\hline 10 & Fortaleza & $\mathrm{CE}$ & Nordeste & 2.551 .805 \\
\hline 11 & Goiânia & $\mathrm{GO}$ & Centro-Oeste & 1.393 .579 \\
\hline 12 & Itabuna & BA & Nordeste & 218.124 \\
\hline 13 & João Pessoa & $\mathrm{PB}$ & Nordeste & 769.604 \\
\hline 14 & Lagarto & SE & Nordeste & 100.330 \\
\hline 15 & Londrina & PR & Sul & 537.566 \\
\hline 16 & Manaus & $\mathrm{AM}$ & Norte & 1.982 .179 \\
\hline 17 & Marabá & $\mathrm{PA}$ & Norte & 251.885 \\
\hline 18 & Martins & $\mathrm{RN}$ & Nordeste & 8.615 \\
\hline 19 & Massaranduba & SC & Sul & 15.586 \\
\hline 20 & Mossoró & $\mathrm{RN}$ & Nordeste & 280.314 \\
\hline 21 & Natal & $\mathrm{RN}$ & Nordeste & 853.929 \\
\hline 22 & Ouro Preto & MG & Sudeste & 73.349 \\
\hline 23 & Picos & PI & Nordeste & 76.042 \\
\hline 24 & Pinhais & PR & Sul & 124.528 \\
\hline 25 & Porto Alegre & RS & Sul & 1.467 .823 \\
\hline 26 & Recife & $\mathrm{PE}$ & Nordeste & 1.599 .514 \\
\hline 27 & Rio Branco & $\mathrm{AC}$ & Norte & 357.194 \\
\hline 28 & Rio de Janeiro & RJ & Sudeste & 6.429 .922 \\
\hline 29 & Salvador & BA & Nordeste & 2.883 .672 \\
\hline 30 & São Paulo & SP & Sudeste & 11.821 .876 \\
\hline 31 & Serra & ES & Sudeste & 467.318 \\
\hline 32 & Timon & MA & Nordeste & 161.721 \\
\hline 33 & Várzea Grande & MT & Centro-Oeste & 262.880 \\
\hline 34 & Vitória & ES & Sudeste & 348.265 \\
\hline
\end{tabular}

*Estimativa da população para 1 de julho de 2013, conforme o IBGE (2013).

Fonte: Elaboração própria. 
Dos 34 municípios identificados no primeiro momento da pesquisa, um número expressivo (26\%) possui mais de 1.000 .000 de habitantes (Figura 1). Quatorze municípios possuem menos de 200.000 habitantes ( $41 \% \mathrm{da}$ amostra), o que pode romper o paradigma de que municípios de pequeno e médio porte não têm estruturado seus controles internos.

\section{Figura 1: Caracterizaçáo dos municípios da amostra por tamanho populacional}

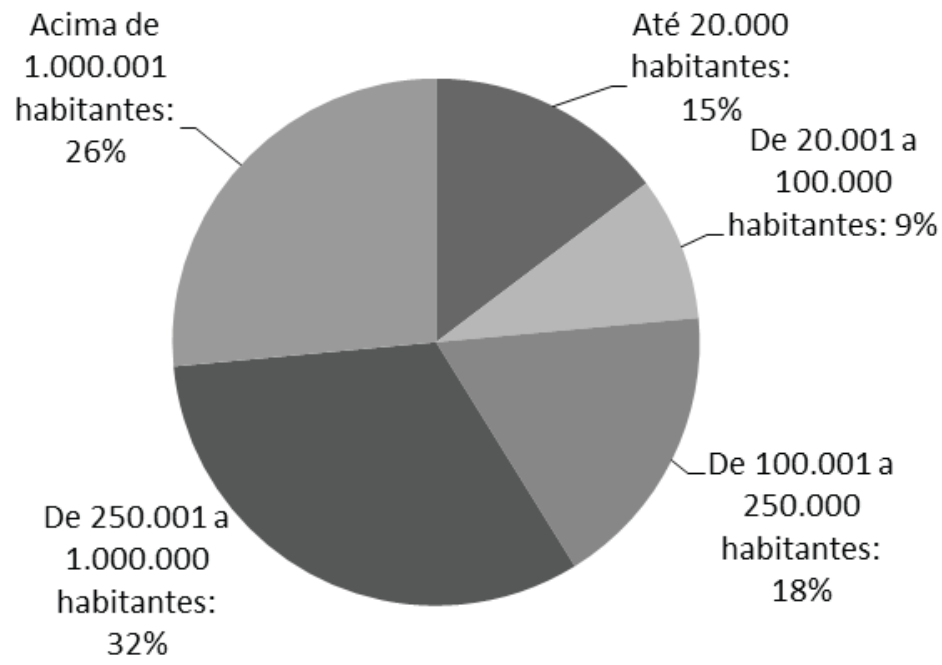

Fonte: Elaboração própria.

Ao analisar a distribuição dos municípios da amostra nas regiōes brasileiras (Figura 2), percebe-se que os casos estão assim distribuídos: há certa concentração no Nordeste (38\%), seguido do Sudeste (23\%) e Sul (18\%). Norte $(12 \%)$ e Centro-Oeste $(9 \%)$ apresentam a menor quantidade de municípios. $\mathrm{O}$ estado que reúne o maior número de controladorias municipais é o Rio Grande do Norte (com quatro municípios), seguido do Espírito Santo, Minas Gerais e Paraná (com três). 
Figura 2: Caracterizaçáo dos municípios da amostra por regiáo brasileira

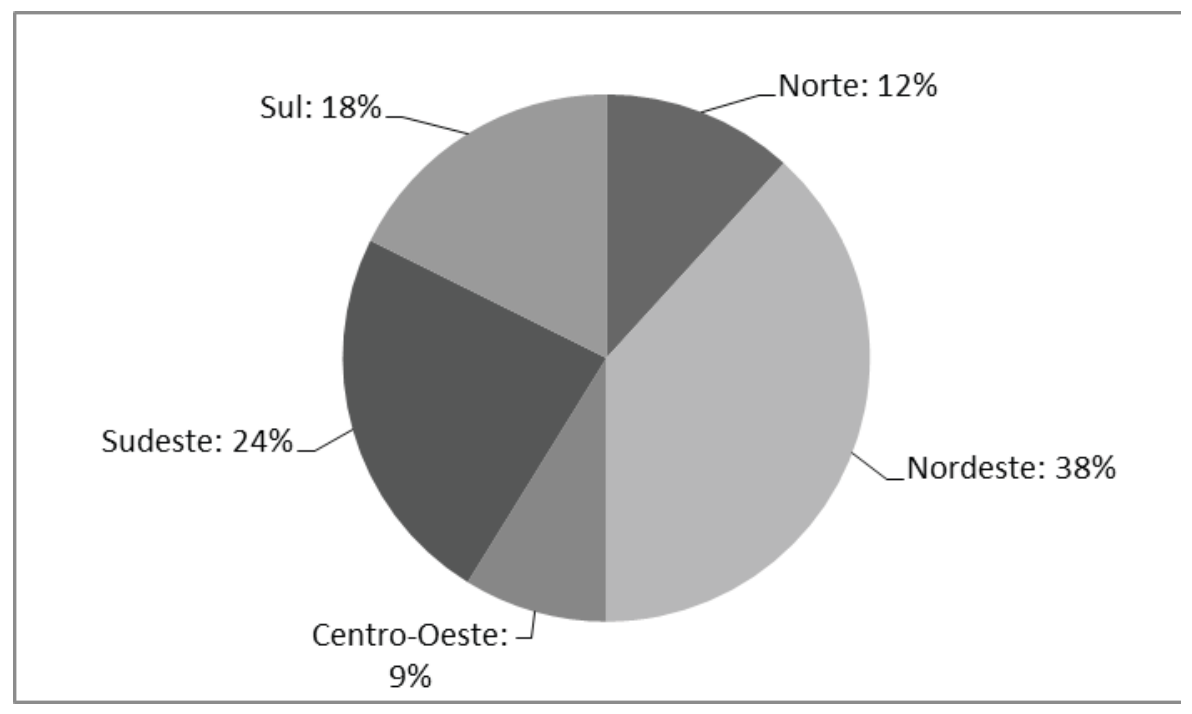

Fonte: Elaboração própria.

Primeiramente, utilizou-se a técnica de observação estruturada para identificar as estruturas de comunicação eletrônica das controladorias dos 34 municípios selecionados. As informaçóes e os documentos disponibilizados nos sites foram analisados e percebeu-se que, para uniformizá-las, seria necessário aplicar um questionário às controladorias, assim garantindo uma abordagem comparada.

Elaborou-se um questionário no qual todos os campos referiam-se a informaçôes que já deveriam estar disponíveis para os servidores das CGMs pesquisadas, não demandando esforços para respondê-las, como: data de criação do órgão, instrumentos legais de institucionalização, posição do órgáo no organograma municipal, estrutura organizacional interna, competências do órgão, dados dos servidores, contratação de serviços terceirizados, orçamentos previstos e realizados, interaçôes do órgão com instrumentos de participaçáo e controle social, realização de processos administrativos ou sindicâncias para apurar irregularidade, e atividades desempenhadas rotineiramente pela CGM.

São, portanto, observadas características centrais: a capacidade institucional dos órgãos (GPP 2003) e as funçôes desempenhadas. A capacidade institucional é pensada por meio da observação de quatro diferentes parâmetros: o instrumento legal de criaçáo das Controladorias, seu posicionamento na estrutura organizacional municipal, o perfil dos recursos 
humanos internos e os recursos financeiros disponíveis. Já as atribuiçôes analisadas utilizam-se como parâmetro aquelas exercidas pela CGU (auditoria, corregedoria, ouvidoria, promoçáo da transparência e fomento ao controle social).

Aproveitando-se da Lei Federal N. ${ }^{\circ} 12.527 / 2011$, também conhecida como Lei de Acesso à Informação (LAI), os questionários foram encaminhados às prefeituras, explicitando que se tratava de um pedido de acesso a informaçóes. Uma vez que a LAI garante o acesso à informaçáo pública e obriga os municípios com populaçáo acima de 10.000 habitantes a disponibilizar determinados dados em meio eletrônico (Ribeiro 2013), essa opção foi uma tentativa de identificar como as CGMs trabalham com a funcionalidade de promover a transparência municipal e o estímulo ao controle social na dimensão da transparência passiva.

Prioritariamente, optou-se por enviar os questionários por meio eletrônico, via e-SIC ${ }^{1}$. Nos casos em que tal link náo foi identificado na primeira página do site da controladoria ou da prefeitura, encaminhou-se o pedido de informaçóes ao Portal de Transparência ${ }^{2}$ municipal. Observouse que muitos municípios não dispunham de formulário específico para contato. Nestes casos foram utilizados outros tipos de contato tais como e-mails da prefeitura, da ouvidoria municipal ou da própria CGM. Em um município, foi solicitado que o formulário fosse levado pessoalmente à prefeitura (e, por isso, o pedido não foi encaminhado). Em outro caso, a solicitação foi enviada para os e-mails pessoais do chefe de gabinete do prefeito e da controladora (obtidos em pesquisas às redes sociais, uma vez que não existia contato eletrônico ou telefônico da prefeitura na Internet).

\section{ANÁLISE DOS RESULTADOS}

\section{RESPOSTAS AO PEDIDO DE INFORMAÇÁO}

A maioria dos municípios pesquisados (56\%) não respondeu ao pedido no tempo previsto (Tabela 2), mesmo com referência explícita à LAI feita no ato do pedido. Consideraram-se válidas apenas as respostas captadas até o dia 17 de dezembro de 2013 (na Tabela 2, os casos em negrito). A escolha da data deve-se ao fato de que a LAI estabelece como prazo regular de resposta a um pedido de informaçóes o período de 20 dias (prorrogáveis

I O e-SIC é o Serviço de Informação ao Cidadão disponível no sites para que os cidadãos possam solicitar as informaçôes que desejarem. No Brasil, municípios acima de 10.000 habitantes devem disponibilizá-lo.

2 O Portal de Transparência visa disponibilizar informaçôes detalhadas sobre a aplicação dos recursos públicos. O primeiro órgáo a cria-lo foi a CGU e, posteriormente, com a Lei de Transparência, os municípios passaram a adotá-lo permitindo ao cidadáo acompanhar a utilização dos recursos. 
Cruz et Al.

por mais 10). Não foram interpostos recursos àquelas localidades que não forneceram as informaçóes dentro do prazo estipulado. 
Tabela 2: Respostas ao pedido de informaçáo

\begin{tabular}{|c|c|c|c|c|c|c|}
\hline ID & Município & UF & $\begin{array}{l}\text { Data do } \\
\text { pedido }\end{array}$ & $\begin{array}{c}\text { Existência } \\
\text { de } \\
\text { protocolo }\end{array}$ & $\begin{array}{l}\text { Existência de } \\
\text { resposta à solicitaçáo } \\
\text { de informaçáo }\end{array}$ & $\begin{array}{c}\text { Tempo de } \\
\text { resposta } \\
\text { (dias) }\end{array}$ \\
\hline 1 & Aracruz & ES & $14 / 10 / 13$ & Não & Sim & 10 \\
\hline 2 & Arez & $\mathrm{RN}$ & $20 / 10 / 13$ & Não & Náo & $\mathrm{NA}$ \\
\hline 3 & Araucária & PR & $14 / 10 / 13$ & Não* & Sim & 25 \\
\hline 4 & Arinos & MG & $14 / 10 / 13$ & Não & Não & $\mathrm{NA}$ \\
\hline 5 & Belo Horizonte & MG & $14 / 10 / 13$ & Não* & Sim & 21 \\
\hline 6 & Boa Vista & $\mathrm{RR}$ & $14 / 10 / 13$ & Náo & Sim & 21 \\
\hline 7 & Canoas & RS & $14 / 10 / 13$ & Sim & Sim & 30 \\
\hline 8 & Corumbá & MS & $15 / 10 / 13$ & Não & Não & $\mathrm{NA}$ \\
\hline 9 & Cristino Castro & PI & $15 / 10 / 13$ & Não & Năo & $\mathrm{NA}$ \\
\hline 10 & Fortaleza & $\mathrm{CE}$ & $15 / 10 / 13$ & Não & Não & NA \\
\hline 11 & Goiânia & GO & $15 / 10 / 13$ & Não & Sim & 6 \\
\hline 12 & Itabuna & $\mathrm{BA}$ & $15 / 10 / 13$ & Sim & Sim & 49 \\
\hline 13 & João Pessoa & $\mathrm{PB}$ & $15 / 10 / 13$ & Sim & Sim & 118 \\
\hline 14 & \begin{tabular}{|l} 
Lagarto \\
\end{tabular} & SE & $15 / 10 / 13$ & Não* & Não & $\mathrm{NA}$ \\
\hline 15 & Londrina & PR & $15 / 10 / 13$ & Não & $\operatorname{Sim}$ & 20 \\
\hline 16 & Manaus & AM & $15 / 10 / 13$ & Não & Não & $\mathrm{NA}$ \\
\hline 17 & Marabá & $\mathrm{PA}$ & $15 / 10 / 13$ & Não & Não & $\mathrm{NA}$ \\
\hline 18 & Martins & $\mathrm{RN}$ & $15 / 10 / 13$ & Não & Não & $\mathrm{NA}$ \\
\hline 19 & Massaranduba & SC & $15 / 10 / 13$ & Não & Sim & 0 \\
\hline 20 & Mossoró & $\mathrm{RN}$ & $15 / 10 / 13$ & Não & Não & $\mathrm{NA}$ \\
\hline 21 & Natal & $\mathrm{RN}$ & $15 / 10 / 13$ & NA & $\mathrm{NA}$ & $\mathrm{NA}$ \\
\hline 22 & Ouro Preto & MG & $15 / 10 / 13$ & Náo & Não & NA \\
\hline 23 & Picos & PI & $15 / 10 / 13$ & Năo* & Não & $\mathrm{NA}$ \\
\hline 24 & Pinhais & PR & $15 / 10 / 13$ & Não & Sim & 0 \\
\hline 25 & Porto Alegre & $\mathrm{RS}$ & $15 / 10 / 13$ & Sim & Sim & 20 \\
\hline 26 & Recife & $\mathrm{PE}$ & $15 / 10 / 13$ & Sim & Sim & 8 \\
\hline 27 & Rio Branco & $\mathrm{AC}$ & $15 / 10 / 13$ & Sim & Sim & 3 \\
\hline 28 & Rio de Janeiro & $\mathrm{RJ}$ & $15 / 10 / 13$ & Sim & Sim & $9^{* *}$ \\
\hline 29 & Salvador & $\mathrm{BA}$ & $15 / 10 / 13$ & Não & Não & NA \\
\hline 30 & São Paulo & SP & $15 / 10 / 13$ & Sim & Sim & 15 \\
\hline 31 & Serra & ES & $15 / 10 / 13$ & Não & Não & $\mathrm{NA}$ \\
\hline 32 & Timon & MA & $15 / 10 / 13$ & Náo & Não & NA \\
\hline 33 & Várzea Grande & MT & $15 / 10 / 13$ & Não & Não & $\mathrm{NA}$ \\
\hline 34 & Vitória & ES & $15 / 10 / 13$ & Sim & Sim & 15 \\
\hline
\end{tabular}


*Não oferece número de protocolo, porém informa por e-mail que recebeu o pedido de informação.

**Respondeu a solicitação feita com a seguinte resposta: "Você poderá ter essas informaçôes através do site da Controladoria: http://www.rio.rj.gov.br/web/cgm”.

Fonte: Elaboração própria.

Entre os 15 municípios que responderam o pedido de informaçóes no tempo previsto pela LAI (ou seja, em até 30 dias), o tempo médio de retorno das solicitaçóes foi de 13,5 dias. Quatro municípios responderam ao questionário na mesma semana do pedido feito (dois responderam no mesmo dia), seguindo o preceito de que a resposta deve ser dada imediatamente, caso já esteja disponível ou de fácil acesso. Onze municípios responderam à solicitação dentro do prazo previsto em Lei (20 dias). Quatro utilizaram a prorrogação. Um município ligou para saber o motivo da solicitação e dois não responderam a maioria das questóes, indicando o site da prefeitura como fonte para obter as informaçóes. A taxa de resposta foi baixa, principalmente considerando que a CGM é, supostamente, o órgão municipal por excelência responsável pelo controle interno e deveria estar atenta ao cumprimento dos requisitos legais trazidos pela LAI.

Regionalmente, as maiores taxas de respostas no prazo foram nas regióes Sul e Sudeste (Tabela 3). O Nordeste, mesmo apresentando maior número de controladorias gerais na pesquisa feita pelo Google, foi a regiáo que relativamente menos forneceu respostas às solicitações feitas. Apenas um dos 13 municípios da região respondeu no o pedido de informação no prazo legal

Tabela 3: Taxa de resposta conforme regiáo brasileira

\begin{tabular}{|l|c|c|}
\hline Região & $\begin{array}{c}\text { Pedidos solicitados } \\
\text { (Pedidos atendidos) }\end{array}$ & Taxa de Resposta \\
\hline Norte & $4(2)$ & 0,50 \\
\hline Nordeste & $13(1)$ & 0,08 \\
\hline Centro-Oeste & $3(1)$ & 0,33 \\
\hline Sudeste & $8(5)$ & 0,63 \\
\hline Sul & $6(6)$ & 1,00 \\
\hline
\end{tabular}

Fonte: Elaboração própria.

Quanto ao tamanho do município, separando os municípios em três grupos populacionais (até 250.000 habitantes, de 250.001 a 1.000 .000 de habitantes, acima de 1.000.0001 habitantes), percebeu-se que houve uma 
variação positiva na correlação entre a taxa de resposta e o tamanho do município, indicando que quanto maior o tamanho do município, maior pode ser sua capacidade em lidar com uma requisição de acesso à informação (Tabela 4).

Tabela 4: Taxa de resposta conforme faixa populacional

\begin{tabular}{|c|c|c|c|}
\hline Grupo & Faixa Populacional & $\begin{array}{c}\text { Pedidos solicitados } \\
\text { (Pedidos atendidos) }\end{array}$ & $\begin{array}{c}\text { Taxa de } \\
\text { Resposta }\end{array}$ \\
\hline 1 & Até 250.000 de habitantes & $14(04)$ & 0,29 \\
\hline 2 & $\begin{array}{c}\text { De 250.001 a 1.000.00 de habitan- } \\
\text { tes }\end{array}$ & $11(05)$ & 0,45 \\
\hline 3 & Acima de 1.000.001 habitantes & $09(05)$ & 0,55 \\
\hline
\end{tabular}

Fonte: Elaboração própria.

\section{CAPACIDADE INSTITUCIONAL DAS CGMs}

Considerando que o grau de institucionalização de um órgão de controle é fundamental para a efetivação das atividades, procurou-se identificar a capacidade institucional (Ingraham 2007) das CGMs que responderam ao pedido de informaçáo feito a partir do tipo de instrumento legal de criação das instituiçóes (lei, decreto, portaria, etc.), da análise dos recursos humanos internos (disposição de funcionários próprios, em comissão, com carreira), dos recursos financeiros disponíveis (unidade financeira autônoma ou não, crescimento ou diminuição dos recursos previstos etc.).

Em relaçáo à data de criaçáo das controladorias, dois momentos parecem ter sido bem significantes, conforme os dados encontrados (Figura 3). O primeiro é o período compreendido entre 2003 e 2006, quando foram criadas oito unidades (três em 2004). Supóe-se que as controladorias oficializadas nesse período sofreram influência direta da criação da CGU, em 2003. 
Figura 3: Criaçáo de CGMs por ano (2001-2013)

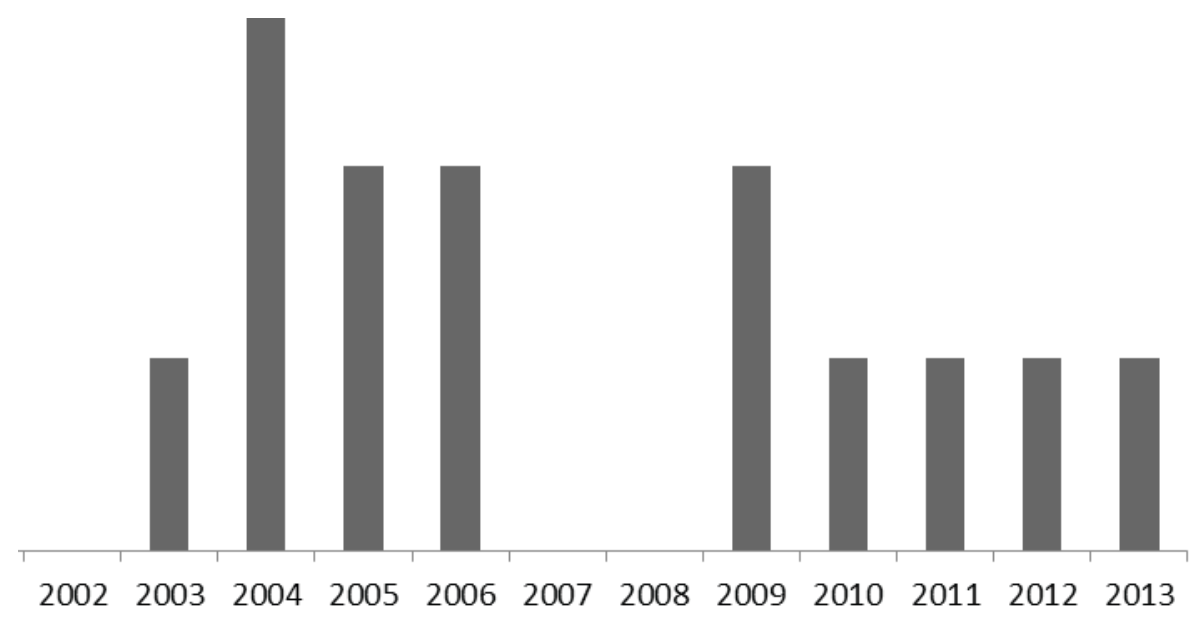

Fonte: Elaboração própria.

No segundo período identificado, de 2009 a 2013, foram criadas as outras seis. Dentre os municípios com mais de 1.000 .000 de habitantes que responderam ao pedido de informaçáo, somente Belo Horizonte criou sua controladoria no primeiro período identificado (2006). Os outros quatro municípios (São Paulo/SP, Recife/PE, Goiânia/GO e Porto Alegre/RS) instituíram seus órgáos a partir de 2009. O Município do Rio de Janeiro/ RJ é pioneiro, pois criou sua controladoria em 1993.

Observa-se que a institucionalização da estrutura organizacional é matéria privativa do Executivo, visto que pode ser formalizada por Lei Municipal Ordinária ou complementar. Apenas três municípios pesquisados instituíram o órgão por Lei Complementar (Massaranduba/SC, Goiânia/ GO e Porto Alegre/RS). O restante preferiu criar a controladoria por meio de Lei Ordinária. Ressalta-se que a Lei Complementar é hierarquicamente superior à Lei Ordinária, por se tratar de alteraçáo direta na Lei Orgânica Municipal, portanto, assume maior relevância legislativa. Desta forma, a maioria possui a base para o desenvolvimento de suas atividades.

De forma a verificar possível relação entre partido e criação do órgão, identificou-se o nome dos prefeitos que assinaram os instrumentos legislativos para, em seguida, consultar sua filiação partidária na época de criação. Foram encontrados sete partidos diferentes (Figura 4), com a predominância de controladorias institucionalizadas em gestóes municipais do Partido dos Trabalhadores (PT). 


\section{Figura 4: Criaçáo de CGMs por partido}

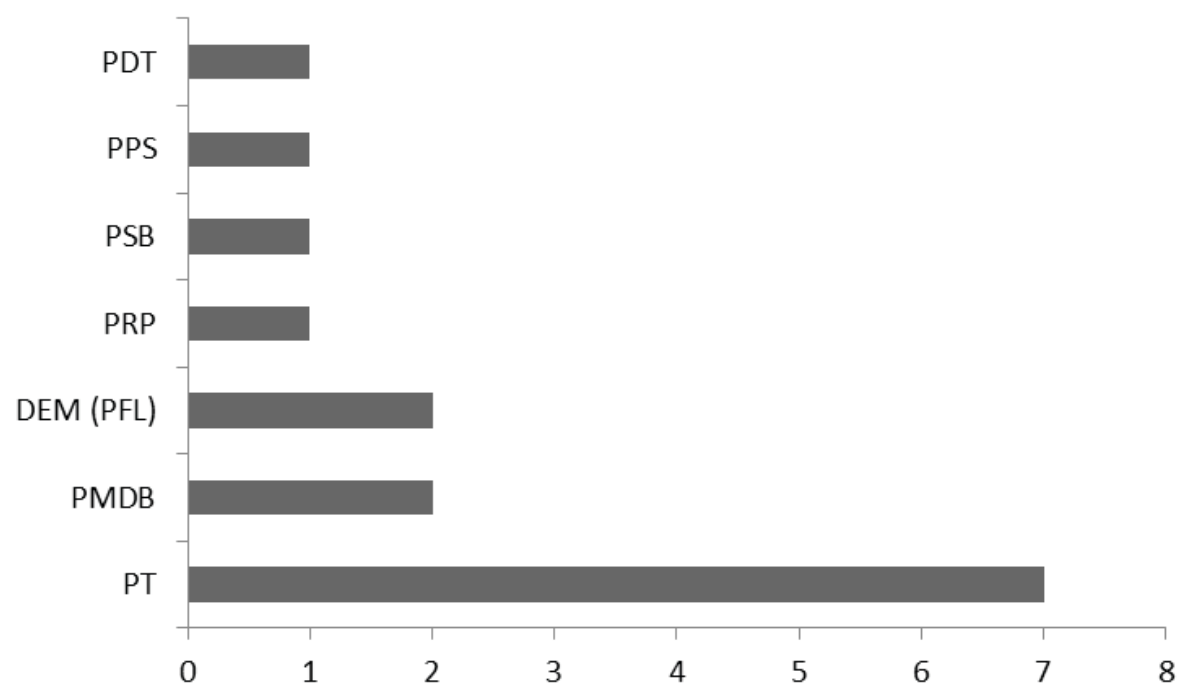

PDT: Partido Democrático Trabalhista; PPS: Partido Popular Socialista; PSB: Partido Socialista Brasileiro; PRP: Partido Republicano Progressista; DEM: Democratas; PMDB: Partido do Movimento Democrático Brasileiro.

Fonte: Elaboração própria

No organograma, observa-se o posicionamento estratégico das CGMs. Há concentração de órgãos no primeiro escalão - secretaria e assessoramento direto ao prefeito. As estruturas de várias localidades foram alteradas no decorrer dos anos, indicando, preliminarmente, o incremento das atribuiçóes. Entretanto, para estudos futuros, pode ser analisada a Lei de estrutura organizacional de cada município e sua evoluçáo no decorrer dos anos.

Em relação às equipes municipais das CGMs, 13 municípios (93\%) não possuem plano de carreira próprio. Dois (14\%) afirmam possuir carreira específica, mas são cargos do Plano de Cargos, Carreiras e Remuneração da Prefeitura que atuam especificamente na CGM (auditor e analista de controle interno). Apenas um município (7\%) afirmou estar em fase de criação da carreira - São Paulo/SP.

O vínculo empregatício da maioria dos servidores é efetivo, $17 \%$ estão em cargos/empregos em comissão, e 12\% são efetivos, mas estão em cargos/emprego em comissáo ou recebem por função gratificada. Portanto, $83 \%$ do pessoal é efetivo. Porto Alegre/RS é o único município que náo 
tem servidor comissionado na CGM, são todos efetivos. Dois municípios (Boa Vista/RR e Sáo Paulo/SP) possuem mais de 45\% do pessoal ocupando cargos em comissão. Há orientação da CF para que esses cargos sejam destinados às atribuiçóes de direção, chefia e assessoramento, recaindo ou não em servidor do município. Os cargos em comissão podem ser preenchidos por servidores de carreira, e as condiçóes e os percentuais mínimos estáo previstos na Lei que estabelece o Plano de Cargos, Carreiras e Remuneração e exigiria análise dessas legislaçóes.

A natureza dos cargos é variada, com concentração de auditores, controladores internos, contadores. Apenas um município (Belo Horizonte/MG) possui diversidade de cargos no órgão (médicos, professores, advogados, etc.).

Há, ainda, variedade na relação da quantidade de servidores e população desses municípios. Existem órgãos com menos de um servidor para cada 100.000 habitantes, até órgãos com 14 servidores por 100 habitantes. Essas informaçóes apontam para a necessidade de um estudo mais aprofundado das atribuiçôes desenvolvidas pelo pessoal existente e o perfil exigido para essas funçóes.

Para completar a análise da capacidade institucional das CGM, outro ponto pesquisado é a existência de orçamento próprio. Dois municípios (Massaranduba/SC e Porto Alegre/RS) não são unidades orçamentárias e estáo vinculados à Secretaria de Fazenda/Finanças. Dez municípios têm orçamentos fixos desde 2012. Destes, em sete houve aumento do orçamento previsto de 2012 para 2013, indicando que o controle interno está ganhando relevância. Dois (Recife/PE e Sáo Paulo/SP) passaram a ter orçamento fixo no ano de 2013.

\section{COMPARAÇÁo COM O MODELO CGU}

Em relação às atribuiçóes e competências legalmente previstas e efetivamente realizadas (Figura 2), segundo o modelo da CGU, dividiu-se a análise em cinco funçôes principais: auditoria, corregedoria, ouvidoria, promoção da transparência e fomento ao controle social. 
Figura 5: Atividades desempenhadas pelas controladorias municipais

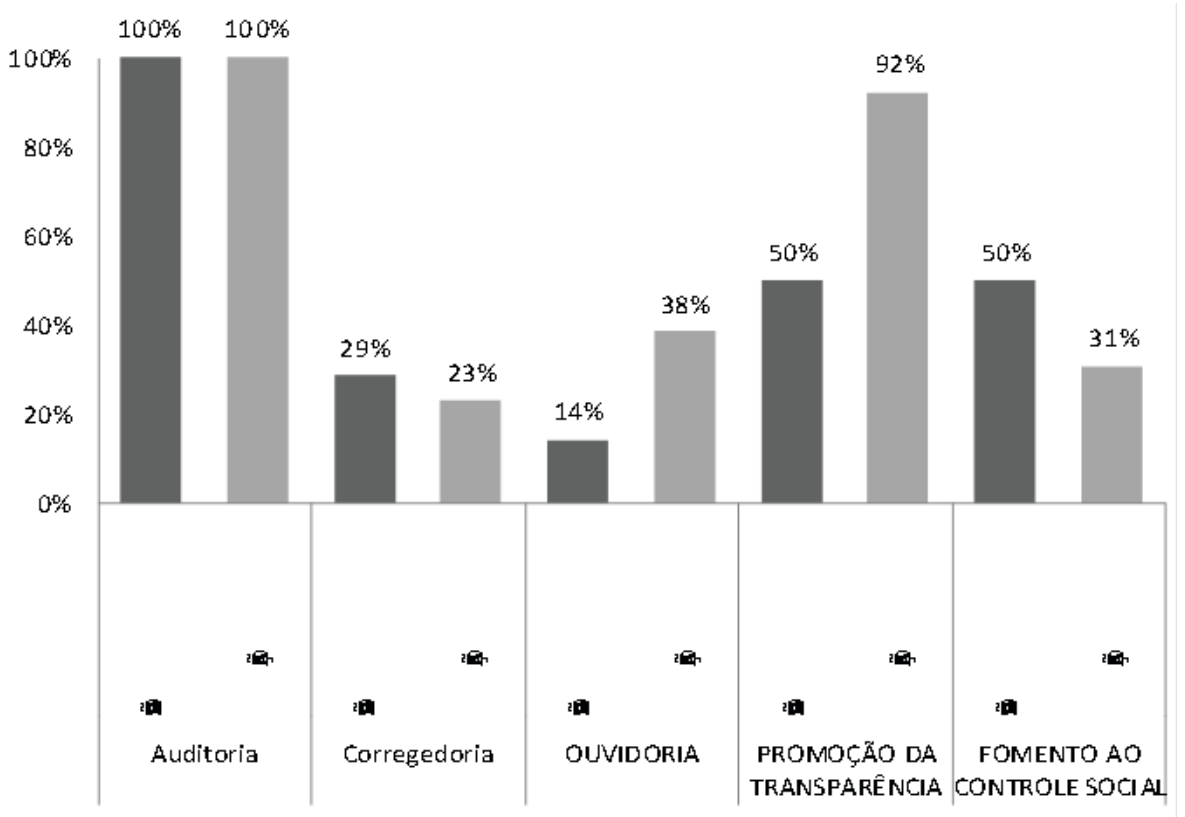

Fonte: Elaboração própria.

A atividade de auditoria continua sendo a funçáo mais desempenhada pelas controladorias. Talvez inspirada no próprio texto da CF que dispóe sobre o controle interno (artigo 74), a totalidade da legislaçáo que cria as controladorias que responderam ao questionário estabelece como próprias as atividades de controle orçamentário, financeiro e patrimonial.

Em alguns casos, inclusive, há replicação do texto constitucional na norma que cria a controladoria. Todas as controladorias examinadas desempenham na prática a função de auditoria. Desse total, $92 \%$ das unidades que responderam ao questionário também examinam licitaçóes e contratos, $75 \%$ efetuam o acompanhamento de programas de governo, $58 \%$ realizam análises contábeis, e $42 \%$ auditam obras públicas.

No aspecto disciplinar, chama a atenção o fato de apenas 29\% das controladorias que participaram da pesquisa possuírem previsão legal para as atividades de corregedoria, mesmo que apenas na posição de órgão central do sistema correicional, e somente $23 \%$ do total realiza de fato essa atividade.

A prática pode estar reduzindo o potencial das controladorias para cercear a impunidade. A experiência da CGU tem demonstrado que manter as atividades de corregedoria e de auditoria em um mesmo órgáo pode 
ser fundamental para agilizar e dar efetividade ao trabalho do controle interno. Talvez esse fato se deva, em alguma medida, à existência de outras unidades correicionais anteriores à criação da controladoria, muitas delas com forte aparato jurídico e que mantiveram suas atribuiçôes legais.

No caso do Município de São Paulo/SP, por exemplo, embora a CGM tenha sido configurada como órgáo central do sistema de corregedoria, com atribuição para instituir procedimentos disciplinares, outros setores que historicamente detinham tal competência mantiveram-na de forma concorrente, a exemplo do Departamento de Procedimentos Disciplinares da Procuradoria do Município e da Corregedoria-Geral da Guarda Civil Metropolitana.

Em outras cidades, como Londrina, a corregedoria é um órgão à parte, náo fazendo parte da controladoria. Na maioria dos casos, como Rio Branco/AC, Massaranduba/PR, Canoas/RS, Vitória/ES e Recife/PE, outros setores são responsáveis pelos processos disciplinares, e em quase todos cabe à Procuradoria-Geral do Município executar a tarefa.

No que diz respeito à ouvidoria, embora apenas dois municípios (14\%) tenham incluído essa atividade na legislaçáo que instituiu a controladoria (Belo Horizonte/MG e São Paulo/SP), em 38\% dos casos ela vem sendo realizada. Nos municípios, pode ser considerada normal a resistência inicial à não inclusão da ouvidoria no escopo de atuação da controladoria.

Isso porque, ao contrário do que ocorre no governo federal, em que a Ouvidoria Geral da União exerce o papel de órgão central do sistema de ouvidorias públicas e, em geral, náo centraliza as demandas relativas, por exemplo, a ministérios e outras unidades federais, as ouvidorias municipais são exaustivamente demandadas sobre assuntos do dia a dia, reclamaçóes relacionadas à prestação de serviços, que afetam o cotidiano dos cidadãos e, em primeira análise, podem não guardar relação com atividades do controle interno.

Esse contexto pode ser a peça-chave para que tal mudança estrutural não venha a ocorrer. A integração das informaçôes da ouvidoria no escopo dos trabalhos do controle interno, no entanto, é de fundamental importância para conferir efetividade ao trabalho do controle interno. Reclamaçóes constantes sobre a execuçáo de determinada política ou a prestaçáo de um serviço podem ser um alerta para que, por exemplo, o contrato firmado com a empresa responsável por sua prestação seja examinado pela auditoria, ou concluir acerca da necessidade de alterar determinado normativo que rege a matéria, ou quanto à importância de proporcionar transparência aos detalhes daquela política pública. 
Com relação às ações preventivas à corrupção, optou-se por concentrar os exames nas políticas de promoção da transparência e de fomento ao controle social. No que diz respeito ao aspecto legal, verificou-se que apenas $50 \%$ dos municípios estabeleceram competência legal para que suas controladorias atuem em políticas preventivas.

Em geral, quando a legislação atribui à controladoria atuar na transparência, também contempla o controle social (71\% dos municípios que incluíram na legislaçáo a competência da controladoria para exercer a promoçáo da transparência também têm, simultaneamente, atribuiçôes relacionadas ao controle social). Embora apenas metade dos municípios examinados tenha atribuição legal nesse sentido, observa-se a tendência a realizar açóes relacionadas à transparência, pelas controladorias municipais ( $92 \%$ dos casos).

Porém, no que diz respeito ao fomento ao controle social, apenas $31 \%$ dos municípios dedicam-se a realizar tal tarefa, embora em $50 \%$ dos casos haja previsão legal para tanto. Identificou-se, ainda, que 69\% das controladorias são responsáveis pelo monitoramento do cumprimento da LAI. A análise de tais dados permite observar que as controladorias vêm desempenhando papel importante na realização de políticas de promoção de transparência e acesso à informação.

Talvez impulsionadas pelo recente movimento de criação de legislaçóes que tratam da matéria e pelo protagonismo da CGU, nesse aspecto, é possível perceber que a promoçáa da transparência desloca-se das secretarias de planejamento para as controladorias, o que, respeitadas as exceçóes, pode ser indicativo de um viés de que a transparência é vista muito mais sob a ótica de controle do que de aprimoramento da gestáo.

Em relação aos instrumentos de participação e interação com a sociedade civil, investigou-se se existiria, nos municípios, algum Conselho de Transparência e Controle Social (CMTCS) ou se, ao menos, as controladorias municipais tiveram participação direta nas reuniôes preparatórias da Primeira Conferência Nacional sobre Transparência e Controle Social (Consocial), realizada em 2012.

Dos municípios que atenderam à solicitação de informação, apenas um possui CMTCS. Criação recente (a experiência pioneira se deu na própria CGU, em 2003), sua disseminaçáo nos municípios passou a ser mais intensa apenas a partir da realização da Consocial, em 2012.

Mesmo sem termos analisado, de forma mais específica, outros canais de participação ou interação com a sociedade civil (exceto em relação à ouvi- 
doria, como já visto anteriormente na análise comparativa das atribuiçóes desempenhadas), algumas controladorias municipais indicaram algumas atividades que vem desenvolvendo junto à sociedade, para além do CMTCS. São elas: seminários sobre a Lei de Acesso à Informação, participação em outros conselhos municipais, frentes de trabalho em bairros e distritos, Café Hacker, interação em canais digitais ou serviços telefônicos de contato direto com o órgáo, disponibilização de relatórios públicos, dentre outras.

Em relação à participação das controladorias nas reuniōes preparatórias para a Consocial já é possível identificar um maior envolvimento das controladorias municipais, pelo menos em relação aos eventos locais (primeira etapa da Conferência). Das quatorze controladorias analisadas, apenas uma não participou, apoiou, promoveu ou organizou a Consocial. A maioria delas (54\%) atuou diretamente na organização do evento.

\section{CONCLUSÁO}

Não obstante o reconhecido do papel desempenhado pela CGU desde a sua criação, a disseminação desse modelo para os municípios brasileiros ainda é incipiente e necessitaria ser melhor estudada em função da identificação dos diferentes estágios de institucionalização das CGMs. Há diferenças significativas nas capacidades institucionais e nas funcionalidades encontradas nas controladorias. Embora, ao longo da última década, possa se perceber uma ligeira tendência na utilizaçáo da nomenclatura controladoria para as unidades de responsáveis pelo controle interno municipal, ainda são poucas as prefeituras que instituíram tais instâncias.

Observa-se que o termo Controladoria Geral pode ter sido disseminado para alguns municípios de forma vertical (da União para municípios), mas também pode ter sido influenciado por Tribunais das Contas, a exemplo do que aconteceu no Paraná. Neste caso, especificamente, corroborou como um dos fatores de disseminaçáo o acesso a informação sobre a inovação ou campanhas de informação promovidas por níveis mais abrangentes de governo ou por outros tipos de entidades e atores (Farah 2007).

Além disso, nos poucos municípios em que as CGMs foram criadas, percebe-se que a simples utilização dessa denominação não implica necessariamente a adoçáo do modelo federal e tampouco garante o adequado funcionamento dessas instituiçóes. A CGU tem um modelo que pode dar respostas a problemas de controle interno enfrentados pela administração local, mas ainda há diversidade na sua implementação em âmbito municipal. Um exemplo disso é o papel dessas instâncias, enquanto garantidoras do acesso à informação, quando elas próprias descumprem sistematica- 
mente o determinado pela LAI. Apenas 41\% (14 de um total de 34) das controladorias municipais identificadas responderam, no prazo estabelecido na LAI, pedidos de informaçôes sobre sua atuação. Tal observação indica problemas no funcionamento dessas unidades, por natureza criadas para garantir, entre outros aspectos, o cumprimento do princípio da legalidade e o acesso à informação pública.

O fato de um grande número de controladorias municipais não cumprirem requisitos básicos fixados em uma Lei que guarda relação direta com sua atividade sinaliza falhas em seu funcionamento que podem comprometer o seu papel enquanto instâncias encarregadas de prevenir e combater à corrupção.

É do conhecimento de todas a importância da contribuição das controladorias para a induzir que a comunicaçáo da Administraçãa com os solicitantes seja clara, objetiva e de fácil compreensão. Sabe-se que é um avanço a divulgaçáo de informaçóes à sociedade por iniciativa própria, realizando um processo de transparência ativa, mas é necessário que termos técnicos, dados orçamentários e financeiros sejam disponibilizados de forma inteligível ao cidadão. Essa preocupação, no entanto, não é uniforme. Duas localidades analisadas não responderam diretamente ao pedido de acesso à informação realizado, informando que as questôes solicitadas estavam disponíveis no sítio oficial e tampouco forneceram subsídios para que ela pudesse ser compreendida ${ }^{3}$.

As informações que circularam na mídia, publicações e materiais disponibilizados eletronicamente da CGU, podem ter proporcionado uma disseminação dos trabalhos desenvolvidos pela União. A CGU aparece como um novo modelo de gestáo do controle interno. Como ressaltado, no entanto, ainda há um longo caminho a percorrer para que as controladorias municipais possam atuar conforme o modelo federal. Embora se saiba que a própria CGU teve suas competências ampliadas no decorrer dos anos, como um processo incremental (Lindblom 1959), ainda são poucas as localidades que têm uma atuaçáo com a mesma abrangência.

Novos estudos mais aprofundados mostrarão se os municípios primeiramente criaram órgáos de Controle interno, de Auditoria Interna ou de Ouvidoria e que as novas demandas levaram a sua reestruturação centralizando as atividades em um órgão e ampliando suas atribuições e competências. A existência de uma institucionalizaçáo anterior pode ter condicionado o novo modelo de CGM que começa a emergir nos municípios.

3 Faz-se necessário conhecimentos especializados de finanças públicas, contabilidade e jurídicos para a correta interpretaçáo dos dados, disponibilizados sem um tratamento adequado para a leitura pelo cidadáo comum. 
Pode, ainda, estar ocorrendo um processo incremental de consolidação dos sistemas municipais de controle que estejam se adequando as especificidades e transformaçóes de cada realidade (Farah 2006).

Muito há para se avançar para que as administraçóes municipais ampliem de uma atuação de repressiva com viés contábil-financeiro no controle interno para exercer outras funçôes, como a prevenção e o combate à corrupção, o monitoramento das políticas públicas, a promoção da transparência e mobilizaçáo da sociedade civil.

Essas iniciativas mostram possibilidades aos municípios para responder a problemas e desafios do controle interno enfrentados por diversos governos locais. Seria importante estudos de casos para verificar se este modelo está sendo disseminado como uma resposta útil às localidades bem como reconhecido pela sociedade (Farah 2006). Aprofundar a análise das motivaçôes que levaram a criação desses órgãos, do papel das lideranças políticas e de suas ideologias, dos partidos dos gestores são questôes que poderiam contribuir com essa discussáo.

Em 2013, ano que a população saiu às ruas solicitando ampliação e melhoria de serviços públicos, combate à corrupção, entre outras demandas, as CGMs podem ser uma resposta a problemas relevantes desde que o controle interno de fato entre na agenda governamental e de decisão (Kingdom 2006: 234) e que haja capacidade administrativa e de recursos diversos (pessoas, financeiros, tecnológicos, de estrutura) para realizaçáo das novas atribuiçóes bem como haja um diálogo permanente e um processo de discussão com a sociedade civil. 


\section{REFERÊNCIAS}

Angélico, F. (2012). Lei de Acesso à Informação Pública e seus Possiveis Desdobramentos à Accountability Democrática no Brasil. Dissertação (Mestrado em Administração Pública e Governo), Escola de Administração de Empresas de São Paulo da Fundação Getúlio Vargas, Brasil.

Balbe, R. (2010). O Resultado da Atuação Controle Interno no Contexto da Administração Pública Federal Brasileira. Dissertação, Departamento de Ciência Política e Políticas Públicas, Instituto Universitário de Lisboa, Lisboa, Portugal.

Branski, R. (2004). Recuperação de Informações na Web. Perspectivas em Ciência da Informação, 9 (1), 70-87.

Brasil. (1988). Constituição da República Federativa do Brasil de 1988. Brasília. Disponível em http://www.planalto.gov.br/ccivil_03/constituicao/constituicao.htm [02-12-2013].

Conselho Federal de Contabilidade (CFC). (2008). Resolução 1.135, de 21 de novembro de 2008. Aprova a NBC T 16.8 - Controle Interno. Brasília: Diário Oficial da União.

Conselho Nacional dos Órgãos de Controle Interno dos Estados Brasileiros e do Distrito Federal (CONACI). (2010). Diretrizes para o Controle Interno Público. Disponível em http://conaci.org.br/wp-content/ uploads/2012/05/DiretrizesparaControleInternonoSetorPublico.pdf [20-11-2013].

Cruz, M., Silva, T. e Spinelli, M. (2013). Pesquisa Controladorias Municipais Brasileiras Frente ao Modelo da CGU. São Paulo: FGV-EAESP.

Farah, M. (2006). Disseminação de Políticas Públicas e Programas Governamentais no Nível Subnacional de Governo. Em ANAIS do X Colóquio Internacional sobre Poder Local. Salvador; UFBA.

Farah, M. (2007). Continuidade e disseminação de inovaçôes na gestão pública subnacional no Brasil. Em Anais do XII Congresso Internacional do CLAD sobre a Reforma do Estado e da Administraçáo Pública. Santo Domingo; CLAD.

Government Performance Project (GPP). (2003). Paths to Performance in State and Local Government: A Final Assessment from the Maxwell School of Citizenship and Public Affairs. Syracuse: The Maxwell School of Citizenship and Public Affairs. 
Instituto Brasileiro de Geografia e Estatística (IBGE). (2013). Perfil dos Municipios Brasileiros 2013. Disponível em http://www.ibge.gov.br/ home/estatistica/economia/perfilmunic/2013/ [12-11-2014]

Ingraham, P. (2007). Studying State and Local Management Systems: Why We Need to Do It. Em Ingraham, P. (Ed.), Pursuit of Performance: Management Systems in State and Local Government. Baltimore: The Johns Hopkins University Press.

International Organisation of Supreme Audit Institutions (INTOSAI). (2007), Diretrizes para as Normas de Controle Interno do Setor Público. Salvador: Tribunal de Contas do Estado da Bahia.

Kingdom, J. (2006). Juntando as Coisas. Em Saravia, E. e Ferrarezi, E. (Orgs.), Politicas Públicas: Coletânea (v. 1). Brasília: ENAP.

Lima, G. (2012). Avaliação dos Órgáos de Controle Interno nos Municípios Brasileiros: Análise a Partir dos Regulamentos Legais. Dissertação, Centro de Ciências Sociais Aplicadas, Universidade Federal de Pernambuco. Recife, Brasil.

Lindblom, C. (1959). The Science of Muddling Through. Public Administration Review, 19 (2), 79-88.

Organização para a Cooperação e o Desenvolvimento (OCDE). (2011). Avaliaçôes da OCDE sobre Governança Pública - Avaliação da OCDE sobre o Sistema de Integridade da Administração Pública Federal Brasileira - Gerenciando Riscos por uma Administração Pública mais Íntegra. Disponível em http://www.cgu.gov.br/publicacoes/AvaliacaoIntegridadeBrasileiraOCDE/AvaliacaoIntegridadeBrasileiraOCDE.PDF [0306-14].

O’Donnell, G. (1998). Accountability Horizontal e Novas Poliarquias. Lua Nova, 44, 27-54.

Oliveira, J. (2012). Controle Interno como Instrumento de Fortalecimento da Accountability: Uma Avaliação Baseada no modelo COSO no Município de Vivência/PE. Dissertação, Centro de Ciências Sociais Aplicadas, Universidade Federal de Pernambuco, Recife, Brasil.

Olivieri, C. (2006). O Controle Interno como Instrumento de Accountability Horizontal: Uma Análise Exploratória da Controladoria Geral da Uniâo. Em Anais do 2० Encontro de Administração Pública e Governança. São Paulo: ANPAD. 
. (2010). A Lógica Politica do Controle Interno: O Monitoramento das Políticas Públicas no Presidencialismo Brasileiro. São Paulo: Annablume.

Organização das Nações Unidas (ONU). (2003). Convenção das Nações Unidas contra a Corrupção. Disponível em http://www.unodc.org/documents/lpo-brazil//Topics_corruption/Publicacoes/2007_UNCAC_ Port.pdf [01-05-14]

Ribeiro, M. (2013). Monitoramento de Políticas Públicas de Governo Eletrônico. Em Anais do VI CONSAD de Gestão Pública. Disponível em http://consadnacional.org.br/wp-content/uploads/2013/05/033-MONITORAMENTO-DE-POL\%C3\%8DTICAS -P\%C3\%9ABLICAS-DE-GOVERNO-ELETR\%C3\%94NICO.pdf [28-11-2013].

Silva, T., Cruz, M. e Spinelli, M. (2014). A Transparência nos Governos Locais: O Cumprimento da Lei de Acesso à Informação pelas Controladorias Municipais Brasileiras. Em Anais do VI Encontro de Administração Pública e Governança. Belo Horizonte: ANPAD.

Soares, L. (2012). Caracteristicas do Sistema de Controle Interno Municipal: Um Estudo na Prefeitura Municipal de Ouro Preto. Dissertação, Faculdade de Ciências Empresariais, Universidade FUMEC, Belo Horizonte, Brasil.

Speck, B. (2002). Caminhos da Transparência: Análise dos Componentes de um Sistema Nacional de Integridade. Campinas: UNICAMP.

Spinelli, M. (2008). Controle Interno. En Avritzer, L., Bignotto, N., Guimarães, J. e Starling, H. (Orgs.), Corrupção: Ensaios e Críticas. Belo Horizonte: Editora UFMG.

Tavares, J. (2005). Uma Proposta de Controle Interno para Regulamentação de Rotinas e Procedimentos do Poder Executivo no Municipio de Florianópolis. Dissertação, Centro de Ciências da Administração, Universidade do Estado de Santa Catarina, Florianópolis, Brasil.

Teixeira, M., Cruz, M. e Silva, T. (2014). Análise das Controladorias Municipais Brasileiras Frente ao Modelo da Controladoria-Geral da União: Avanços e Desafios na Promoção da Transparência e do Controle Social. Em Anais XIX Congreso Internacional del CLAD sobre la Reforma del Estado y de la Administración Pública. Quito: CLAD.

Thiel, S. (2014). Research Methods in Public Administration and Public 
Management: An Introduction. New York: Routledge.

Veloso, J., Monastério, L., Vieira, R. e Miranda, R. (2011). Gestão Municipal no Brasil: Um Retrato das Prefeituras. Brasília: IPEA.

Vieira, V. (2013). Efeitos da Lei de Acesso à Informação (Lei 12.527/2011) nas Compras Públicas. Em Anais do VI CONSAD de Gestâo Pública. Brasília: CONSAD.

Recibido: 14-03-2014

Aceptación de la versión final: 05-12-2014 